\title{
Physicians' Attitude Towards Evidence-Based Medical Practice and Health Science Library Services
}

\author{
Vahideh Zarea Gavgani * \\ Vangari Vishwa Mohan ${ }^{* *}$
}

\begin{abstract}
Background and Objectives: It has been more than a decade since evidence-based medical practice (EBMP) became a top curriculum in medicine. Developing countries, however, have problems practicing EBM since it needs skills, time, and resources. Libraries and librarians can play a vital role in providing physicians with evidence-based information. This user study was directed at exploring physicians' attitudes towards EBMP, their awareness and practical knowledge in finding and evaluating evidence/information, and the implication of these findings for health science library services.

Methodology: A survey method was adopted to carry out the study. A structured questionnaire was used to collect data. The target population was comprised of physicians and specialists from government and private hospitals in Hyderabad, India. One hundred twenty-four responses were received. MS Excel and SPSS software were used for statistical analyses.

Results: The study revealed that physicians have positive attitudes toward EBMP. They also agree that EBMP is obligatory on the part of physicians - professionally, ethically, and legally. They indicated a high usage rate of print and electronic sources, which suggests that health science libraries should be equipped to support physicians in EBMP. Conclusion: This study concludes that efficient librarian information support services should be provided to physicians in order to enable them to practice evidence-based medicine.
\end{abstract}

Keywords: User studies. User attitude. Evidence-Based Medical Practice (EBMP). Health science library services.

\footnotetext{
* Research Scholar, Department of Library \& Information Science, Osmania University, Hyderabad; Librarian, Tabriz Faculty of Medicine, Iran; e-mail: vgavgani@yahoo.com

** Professor and Chairman of Board of Studies, Department of LIS, Osmania University, Hyderabad-500 007; e-mail: drvvm321@yahoo.com
} 


\section{Introduction}

Evidence is the basis for almost every human decision and action. A field such as the medical profession that deals with the health and lives of individuals should ensure the utmost care in diagnosing and treating a patient. To provide incorrect treatment can be devastating. Evidence-based medical practice helps ensure that the right treatment is given to the right patient. This does not mean that physicians treat their patients without any foundation. Almost every physician bases his/her treatment on the knowledge and experience s/he has already gained. But keeping oneself up-to-date on current information and knowledge is indispensable. New diseases, new techniques, and new methods are constantly emerging. Unless physicians keep themselves abreast of the latest developments, they may not be in a position to render the most effective and efficient services. The most considerable hallmark of the information revolution in medicine is known as the "basic leap from bedside to computer" (Jordan, 2002). This phenomenon has provided an appropriate environment for the development of evidence-based medicine (EBM).

If a physician has to diagnose the medical problem of another person based only on his/her previous knowledge about symptoms and signs and trusting what the affected individual reports regarding the problem, inaccurate diagnoses are likely to occur due to the inadequacies of both the physician and the patient. Physicians, for example, tend to lean on their memorized knowledge and past experiences, frequently lacking sufficient time to keep themselves up-to-date. At the same time, patients may frequently fail to report important symptoms due to ignorance or lack of knowledge. In contrast, evidencebased medicine has been defined as "the conscientious, explicit, and judicious use of current best evidence in making decisions about the care of individual patients" and as "the integration of the best research evidence with clinical expertise and patient values" (Sackett \& Rosenberg, 1996, p. 71). Thus, the aim of EBM is to eliminate or reduce uncertainty in medical practice.

Evidence-based medical practice (EBMP) has gained prominence throughout the world, especially in advanced countries. Inclusion of EBMP in the course curricula of medical schools reflects this prominence. There is, however, a need to determine how physicians in developing countries regard EBMP so that health science libraries can appropriately equip themselves with the necessary skills, tools, and resources to support physicians interested in EBMP. This study has been conducted to elicit facts relating to physicians' attitudes towards EBMP in India, a country in which there is a high level of awareness as well as advanced technological development, especially in the area of information technology and medicine.

\section{Objective, scope, and methodology}

The user study is directed toward exploring physicians' approaches and attitudes towards EBMP in order to draw inferences regarding the impact of their involvement with EBMP on library and information services.

The scope of the study is confined to Indian physicians' attitudes towards EBMP. It includes physicians from both government and private hospitals in Hyderabad, India. 
To study the attitude of physicians regarding the practice of EBM in India, a survey study was carried out among physicians working in top government and private hospitals in Hyderabad (India), a representative city with a metropolitan/cosmopolitan makeup. The questionnaire tool was used to gather data from a random sample of 150 physicians. One hundred twenty-four of this group responded. Twenty-six of the respondents either stated they were unfamiliar with EBM or left the question unanswered. Consequently, the analysis was conducted using data gathered from the 98 respondents who were aware of EBM. SPSS software and Microsoft Excel were used to analyze the data.

\section{Analysis}

As mentioned in the methodology, required data were collected through a structured questionnaire. In this section, data on important aspects are presented and analyzed.

\section{Physicians' familiarity with EBMP}

The following diagram (Figure 1) is a representation of the respondents (79\%) who asserted they are familiar with EBMP and those who are not familiar (21\%). Those respondents in the $21 \%$ group are senior physicians who were not exposed to EBMP during their education and medical practice.

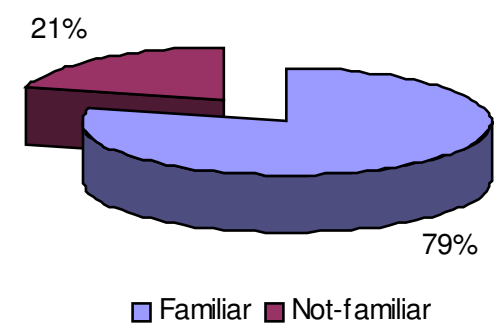

Figure 1. Familiarity of physicians with EBMP

\section{Physicians' approaches towards EBMP}

The following table (Table 1) presents data on physicians' approaches towards evidencebased practice.

Table 1: Showing data on physicians' approaches towards EBMP

\begin{tabular}{|l|l|l|l|l||}
\hline Question & Yes & $\%$ & No & \% \\
\hline Do you practice EBM in your decision making about your patients? & 90 & 91.8 & 8 & 8.1 \\
\hline Do you agree that without EBM practice is inefficient? & 68 & 69.3 & 12 & 12.2 \\
\hline $\begin{array}{l}\text { Do you agree that evidence-based practice is obligatory in } \\
\text { medicine? }\end{array}$ & 96 & 97.9 & 2 & 2 \\
\hline
\end{tabular}

The data in the above table illustrate that $91.8 \%$ of those physicians familiar with EBM practice apply EBM in their decision-making about their patients, and $69.3 \%$ agree that 
without EBM their practice would be inefficient. Surprisingly, $18 \%$ did not provide any response. Regarding the obligatory application of EBM, 97.9\% stated that it is a must. These responses indicate that physicians even in developing countries are familiar with EBMP and that they have a positive attitude towards it.

\section{Physicians' viewpoint on the obligatory application of EBM}

The data collected to determine what makes physicians feel that EBM is obligatory for medical practice is shown in Figure 2. Here, $81.6 \%$ of respondents indicated that EBM is professionally obligatory, $79.6 \%$ replied that EBM is ethically obligatory, $67 \%$ believe that it is legally obligatory, and $20 \%$ reported that it is economically obligatory. Finally, $29.6 \%$ believe that it is just a self satisfaction movement in medical practice.

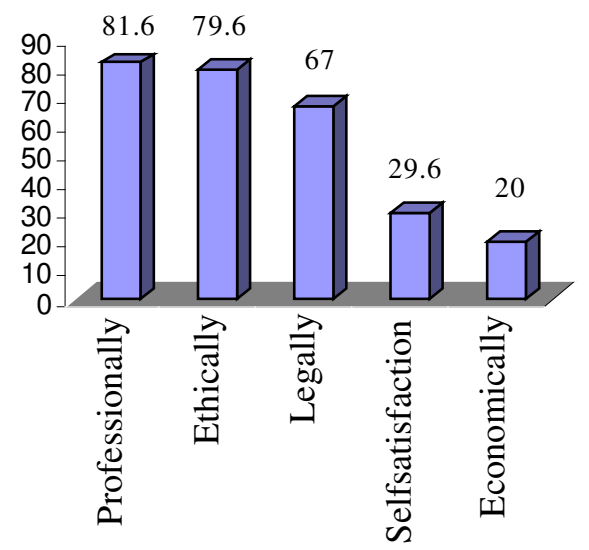

Figure 2. Physicians' viewpoint regarding EBMP in India

\section{The state of practice of EBM in India from physicians' viewpoint}

Only $45 \%$ of those responding, view that EBM is widely practiced in India, $37 \%$ believe that it is rarely practiced, and one percent stated that it is not practiced at all. Though only $45 \%$ of the respondents stated that it is widely practiced, the overall percentage $(82 \%)$ of physicians agree that EBM is practiced in India, even if rarely. This indicates that the majority of doctors in India practice EBM at least some of the time.

\section{Sources of information that physicians consult in connection with EBMP}

The data regarding the sources physicians consult in practicing EBM revealed that $73.5 \%$ of physicians consult print resources, including books, journals, theses, atlases, and guidelines, while $63 \%$ use online and electronic resources that include free Web, PubMed, Medline, e-Journals, The Cochrane Library, and resources related to systematically reviewed literature.

\section{Physicians' preference for printed sources}

Among printed resources, books were the most commonly used source (100\%), followed by journals (86\%), theses/research reports (47\%), guidelines (44\%), atlases (25\%), and others (5\%) (see Figure 3). 


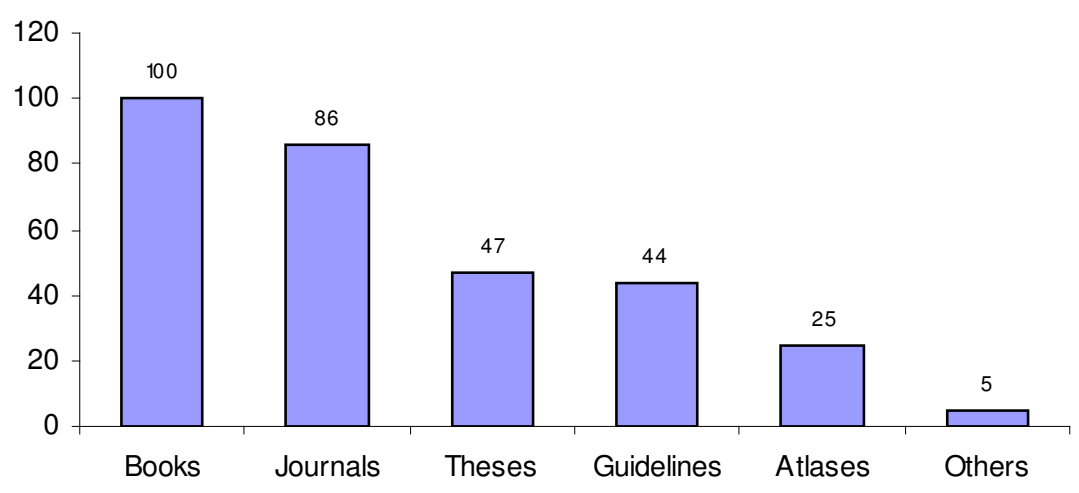

Figure 3. Physicians' preference for print sources

\section{Reasons for physicians' preference for the use of print sources}

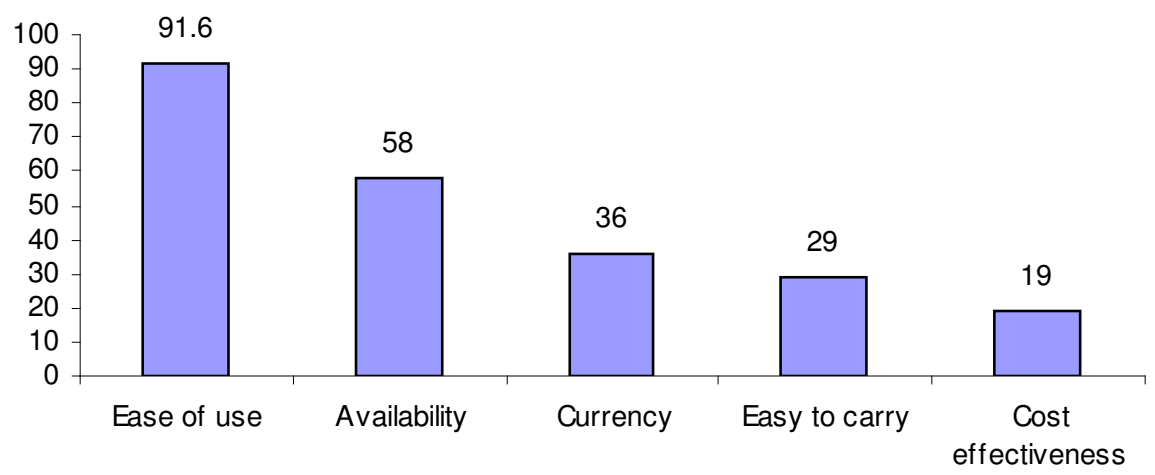

Figure 4. Reasons for physicians' preference for the use of print sources

In response to the question of why they prefer to consult print sources, $91.6 \%$ distinguished print sources as easy to use in that they can be easily carried and read without the need for any reader/device at the bedside of the patient. About $58.3 \%$ found them to be the most readily available sources for medical information (see Figure 4).

\section{Physicians' preference for electronic/Web-based sources of information}

In relation to electronic and Web-based sources of information, 84\% of the respondents preferred to consult the free Web, 74.2\% PubMed, 64.5\% Medline and other relevant databases, 32\% e-journals, 29\% The Cochrane Library, and 22.5\% specific Web sites, including Medscape, emedicine, MD Consult, and American Heart Association (AHA). The following diagram illustrates the physicians' information-seeking behavior on the Web. 


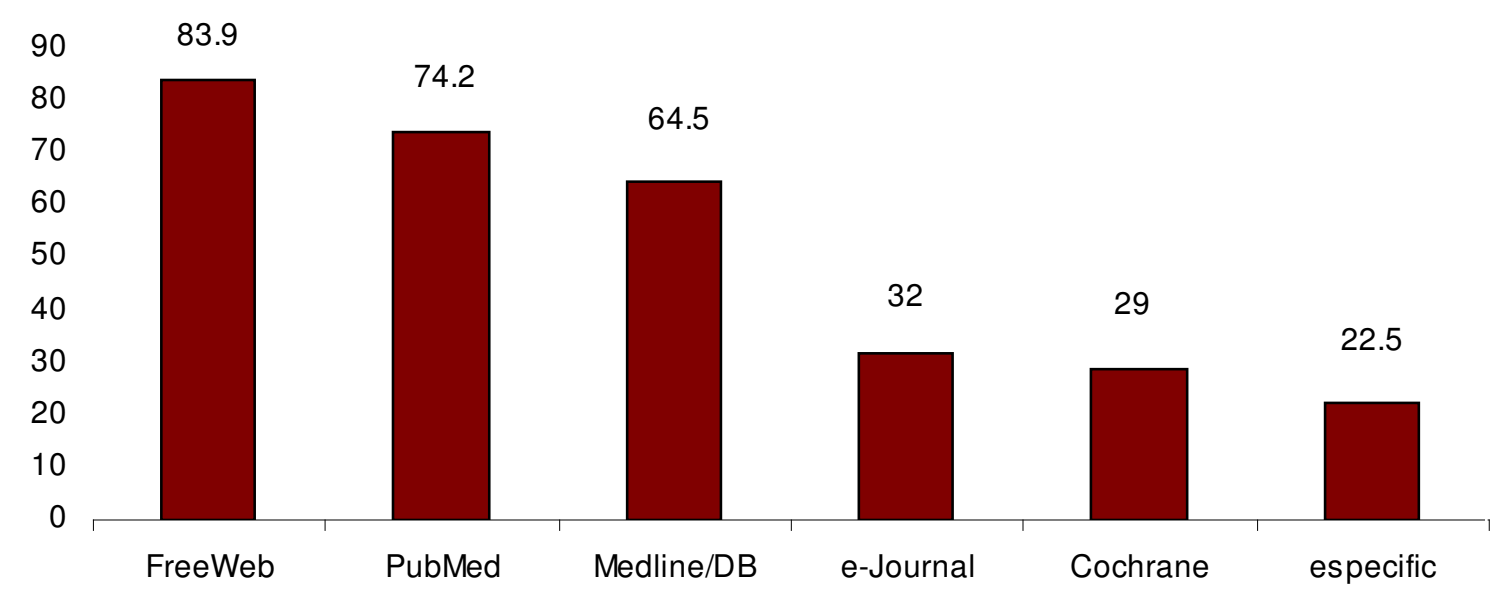

Figure 5. Physicians' preference in relation to electronic/Web-based sources of information

\section{Methods physicians use to appraise evidence}

As shown in Figure 6 below, $42.85 \%$ of respondents reported that they use statistical methods to evaluate evidence retrieved from literature, $30.6 \%$ use National Health and Medical Research Council (NHMRC) methodology, 22\% use an arbitrary method, and only six percent use PICO (problem, intervention, comparison group, and outcomes) criteria.

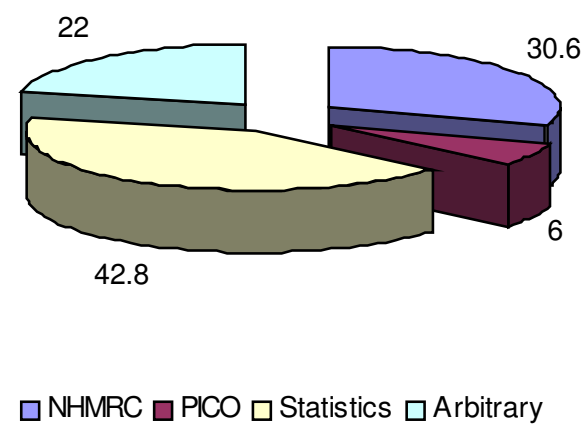

Figure 6. Methods physicians use to appraise evidence

\section{Physicians' opinion regarding governmental enactment of EBMP}

Fifty-one percent of respondents claimed there should be legislation regarding EBMP, and $30.6 \%$ claimed it to be part of existing legislation.

\section{Findings}

The study gave rise to the following findings:

$\checkmark$ The majority of the respondents (79\%) are familiar with EBM. In contrast with earlier studies in such developing countries as Iran (Zarea, 2006) that revealed 
physicians are not well aware of EBM, this study revealed that in Hyderabad, India the majority of physicians are familiar with evidence-based medicine.

$\checkmark$ The physicians have a positive attitude towards EBMP. Almost all physicians (91.8\%) familiar with EBM practice apply EBM in decision-making about their patients.

$\checkmark$ The majority of the respondents agree that EBMP is obligatory professionally, ethically, or legally.

The majority of the respondents (82\%) agree that EBM is practiced in India, even if rarely.

$\checkmark$ The majority (73.5\%) of respondents consult print resources in connection with EBMP. Of those who preferred to use print media, 100\% are using books. In an ever-changing and ever-growing field such as medicine, books as a source of information are more useful for learning background knowledge such as principles, fundamentals, and history rather than foreground knowledge such as trends and latest approaches. Since the decision-making process needs foreground knowledge, books should be considered only as secondary sources for extracting information.

$\checkmark$ Even in the digital environment, $91.6 \%$ distinguished printed sources as those that are easiest to use.

$\checkmark$ Almost $84 \%$ of the respondents preferred to consult the free Web, $74.2 \%$ PubMed, 64.5\% Medline and other relevant databases, 32\% e-journals, 29\% The Cochrane Library, and 22.5\% specific Web sites. Regarding the latter, they mentioned Medscape, emedicine, MD Consult, and AHA as specific Web sites of evidence-based medicine. The findings are similar to those of Zarea (2006) in Iran, McColl, Smith, White, \& Field (1998), and Wilson, Glanville, and Watt (2003) in the United Kingdom. McColl et al. (1998) found that the UK's general physicians have little knowledge about information finding using Internet-based sources. Wilson et al. (2003) pointed out that $49 \%$ of the general physicians at York University are not able to use NHSnet and that they need to be educated in using databases such as Medline. Thirty-one percent of their respondents need to be educated about the general use of the Internet.

In our study, of those physicians who reported that they prefer to consult online/Web resources, the major part of the population identified the free Web as a source of evidence; PubMed, e-journals, and Medline followed in order of preference. In the present study, The Cochrane Library took last place after specific Web sites as a source of evidence. It needs to be noted that the free Web is an unmanageable ocean of information as well as of misinformation. The free Web is not a suitable source of evidence unless one consults specific databases or Web sites of systematically reviewed articles in general medicine and in specific 
fields. Though The Cochrane Library is an international collaborative involved in the systematic reviewing, appraising, and disseminating of accurate and reliable evidence in all branches of medical science, it is indicated as the least preferred electronic/Web-based resource. Only a small portion of respondents (29\%) referred to The Cochrane Library. There are also specific evidence-based sites such as www.paediatricevidencebasedmedine.com. About $13.2 \%$ of respondents asserted they are using specific Web sites of EBM; but in response to the listing of the specific Web sites they consult, they referred to free medical sites such as MD Consult and medscape instead of specific EBM Web sites. The findings in this regard indicate that since physicians are not aware of specific Web sites and Webbased sources of information, they use irrelevant sources of evidence. Although such sources may be good, they may not be the best sources of evidence.

$\checkmark$ There is no single method that is largely used by physicians to evaluate evidence. The same results were pointed out by Milne and Oliver (1996); Aki, Izuchukwu, El-Dika, and Fritsche (2004); Devitt and Murphy (2004); and Hanson, Bhandari, Audige, and Helfel (2004) in their studies.

Finally, $81.6 \%$ of respondents claimed there should be legislation on EBM either as separate legislation or as part of existing legislation. The legislation when acted as the Evidence Based Medical Practice Act, will provide Clinical Practice Guidelines and a statutory protection to the patients from medical malpractices.

\section{Recommendations}

Physicians' familiarity with and positive attitude towards EBMP are significant indications that physicians are dedicated to their profession. To practice EBMP, they need accurate information resources to form the basis of required evidence.

Consequently, there should be suitable library and information support services for physicians. Health science libraries must equip themselves with the necessary skills and information resources to meet the EBMP needs of physicians.

There are many hospitals in developing countries such as India where there are no libraries and information support services. There is a definite need on the part of hospitals to establish libraries. To ensure this, state governments should not give permission to establish hospitals unless the conditions of establishing a clinical library within the hospitals and appointing qualified and skilled library/ information professionals are fulfilled.

Though librarians play their role of intermediate/informationist in searching for information and information dissemination, physicians should also be empowered with information-searching and retrieving skills. Effective training should be provided to physicians by relevant library and information centers, especially for senior physicians who were not exposed to EBMP during their education and practice. In addition, librarians should participate in preparing necessary guidelines that will be most useful for EBMP. 
Physicians use different methods in appraising evidence. Some of them do it arbitrarily. Consequently, an evidenced-based librarian who has been trained in medical library and information science and medical terminology should help these physicians in evaluating the evidence. Since a majority of physicians prefer print documents, clinical librarians should also develop required print collections. In other words, print media should not be ignored in the wake of electronic media.

Every hospital library should be provided with evidence-based medical librarians (EBML) who have been trained in medical library and information science and medical terminology with particular emphasis on EBM. Any department in a hospital may have its own special evidence-based medical librarian (EBML). EBMLs should participate in the practice of going on rounds and noting patients' problems in order to provide physicians with specific and qualified evidence. EBMLs should have the authority to access patients' electronic medical records (EMR) in order to be able to search for and provide physicians with relevant evidence.

Further, there are case studies in India, both typical and unique, that can serve as excellent sources of evidence for physicians all over the world. Although India's medical practice has many expert physicians, the number of their international publications is not considerable. The opportunities to publish articles and case studies in ISI journals or other journals indexed in Index Medicus, EMBASE, and Excerpta Medica are fewer for Indian doctors than for doctors in developed countries. A database of systematic reviews of case studies and Indian journal articles can be supplementary and complementary to The Cochrane Library and a good national evidence-based information system (NEBMISI) for Indian physicians.

\section{Conclusion}

Life is invaluable and health is real wealth. Modern society respects human rights. Every human has a right to equality and a right to freedom of religion. In addition, every human has a right to good health. When someone suffers from ill health, however, it is members of the medical profession who restore normalcy or health to the suffering. Medical mistakes are very serious, and the medical profession is very conscious of this in treating those who are ill. EBMP is that medical practice that aims at minimizing medical mistakes. Consequently, the practice of EBMP should be considered as crucial, and clinical librarians should endeavor to render effective and efficient information support services to physicians.

\section{References}

Aki E.A., Izuchukwu I.S., El-Dika, S., Fritsche L. (2004). Integrating an evidence-based medicine rotation into an internal medicine residency program. Academic Medicine, 79(9) 897-90. Accessed November 2004 from: http://www.ncbi.nlm.nih.gov/sites/entrez.

Devitt, N., \& Murphy, J. (2004). A survey of the information management and technology training needs of doctors in an acute NHS trust in the United 
Kingdom. Health Information and Libraries Journal, 21, 164-172. Retrieved November 2004 from http://www.blackwell.synergy.com

Hanson, B. P., Bhandari, M., Audige, L., \& Helfel, D. (2004). The need for education in evidence based orthopedics: An international survey of AO Course participants. Acta Orthopedic Scandinavica, 75(3), 328-332. Retrieved November 2004 from http://www.ncbi.nlm.gov/enterz/query

Haynes, B. R., \& Wilczynski, N. L. for the Hedges Team. (2004). Optimal search strategies for retrieving scientifically strong studies of diagnosis from Medline: Analytical survey. British Medical Journal. Retrieved December 2006 from http://www.bmj.com

Jordan, T. J. (2002). Understanding medical information: A user guide to introduction and decision-making. New York, McGraw-Hill, 3.

McColl, A., Smith, H., White, P., \& Field, J. (1998) General practitioners' perceptions of the route to evidence based medicine: A questionnaire survey. British Medical Journal, 316, 361-365. Retrieved November 2004 from http://bmj.bmjjournals.com/cgi/reprint/316/7128/361

Milne, R., \& Oliver, S. (1996). Evidence-based consumer health information: Developing teaching in critical appraisal skills. International Journal for Quality in Health Care, 8(5), 439-445.

Sackett, D. L., \& Rosenberg, D. W. (1996). Evidence-based medicine: What it is and what it isn't. British Medical Journal, 312, 71-72. Available from: http://www.bmj.com/cgi/content/full/312/7023/71

Wilson, P., Glanville, J., \& Watt, I. (2003). Access to the online evidence base in general practice: A survey of the Northern and Yorkshire Region. Health Information and Library Journal, 20(3):172-8. Retrieved September 2003 from http://www.blackwell-synergy.com/doi/abs/10.1046/j.1365-2532.2003.00448.x

Zarea, V. (2006). Evidence based medical approach among clinical faculty members. Medical Journal of Tabriz University of Medical Science and Health Science. 28(1), 61-68. Available online at http://medicaljournal.tbzmed.ac.ir/PDF/bahar\%2085/eng/11.pdf 